\title{
ÁGUA SUJA TAMBÉM LAVA: UMA ANÁLISE DO DESPERDÍCIO DE ÁGUA SOB A PERSPECTIVA DE MARKETING SOCIAL
}

DIRTY WATER ALSO WASHES: AN ANALYSIS OF WATER WASTE FROM

THE PERSPECTIVE OF SOCIAL MARKETING

\section{Joice dos Santos Alves}

Mestranda em Gestão Pública e Cooperação Internacional pela Universidade Federal da Paraíba (UFPB). Graduada em Administração pela Universidade Federal da Paraíba (UFPB). E-mail: admjoicealves@gmail.com.

\section{Luana Patrícia da Silva}

Mestranda em Gestão Pública e Cooperação Internacional pela Universidade Federal da Paraíba (UFPB).

Graduada em Administração pela Universidade Federal da Paraíba (UFPB).

E-mail: admluanapatricia@gmail.com.

\section{Guilherme Nunes Araújo}

Graduando em Administração pela Universidade Federal da Paraíba (UFPB).

E-mail: guinunes98@hotmail.com.

\section{Stephanie Ingrid Souza Barboza}

Doutora em Administração pela Universidade Federal da Paraíba (UFPB). Mestre em

Administração pela Universidade Federal da Paraíba (UFPB). Graduada em Administração pela

Universidade Federal de Campina Grande (UFCG). E-mail: stephanieisb@gmail.com. 


\section{RESUMO}

As disparidades de oferta da água e o seu padrão de consumo desregular têm levantado discussões relevantes e causaram o interesse entre os estudiosos de marketing social, que visam abordar causas sociais com o intuito de realizar mudanças comportamentais positivas. Nesse sentido, este estudo objetivou discutir aspectos que influenciam a redução do desperdício e do consumo de água sob a perspectiva de marketing social. O referencial teórico discute elementos sobre o marketing social e o consumo de água potável, além de debater sobre a redução do desperdício de água. A metodologia adota uma abordagem qualitativa de caráter exploratório com vistas a entender como o consumidor gerencia o consumo de água. As entrevistas ocorreram entre os meses de novembro de 2017 e janeiro de 2018, e foram entrevistados 35 indivíduos residentes no Nordeste. Como resultados, pode-se afirmar que os indivíduos adotam estratégias de consumo para amenizar o desperdício de água, entretanto, observa-se que há a necessidade de incentivos governamentais para disseminar conhecimentos práticos e teóricos a respeito do consumo consciente da água potável.

Palavras-chave: Marketing social. Consumo de água. Desperdício de água. Reutilização.

\section{ABSTRACT}

Disparities in the supply of water and its deregulatory consumption pattern have raised relevant discussions and caused interest among social marketing scholars, who aim to address social causes with a view to making positive behavioral changes. In this sense, this study aimed to discuss aspects that influence the reduction of waste and water consumption from the perspective of social marketing. The theoretical framework discusses elements about social marketing and drinking water consumption, as well as discussing the reduction of water waste. The methodology adopts a qualitative exploratory approach. The interviews took place between November 2017 and January 2018, in which 35 individuals living in the Northeast were interviewed. As results, it can be affirmed that individuals adopt consumption strategies to minimize water waste, however, it is observed that there is a need for government incentives to disseminate practical and theoretical knowledge regarding the conscious consumption of drinking water.

Keywords: Social marketing. Water consumption. Reuse. 


\section{INTRODUÇÃO}

As discussões em torno da problemática da água têm evidenciado um elevado nível de instabilidade nos recursos hídricos, não somente nas áreas que experimentam frequentemente crises de fornecimento. De maneira geral, as dificuldades de gerenciamento de água residencial foram atribuídas ao clima instável, às mudanças demográficas e à evolução dos equipamentos domésticos (MOSTAFAVI et al., 2018). Além do mais, os impulsionadores da crise global da água, incluindo mudanças climáticas, aumento da globalização e falta de saneamento básico, dependem de fatores socioeconômicos e hidrológicos locais (KOFINAS; SPYROPOULOU; LASPIDOU, 2018).

Em nível global, o debate em torno da água está previsto na Agenda 2030 como um dos Objetivos do Desenvolvimento Sustentável (ODS) e tem como finalidade assegurar a disponibilidade e gestão sustentável da água e saneamento para todos (ONU, 2015). O Brasil é um país privilegiado quanto ao volume de recursos hídricos, pois abriga 13,7\% da água doce do mundo. Entretanto, a disponibilidade de água não é uniforme, o que impacta no desenvolvimento dos estados. Enquanto na região Sudeste 87,5\% dos domicílios são atendidos por rede de distribuição de água, no Nordeste a porcentagem é de apenas $58,7 \%$ (ANA, 2017).

De acordo com o relatório da Agência Nacional de Águas (2017), no ano de 2016 a escassez hídrica atingiu 18 milhões de habitantes, sendo 84\% dos impactados moradores do Nordeste brasileiro, lugar cujo reservatório apresentou redução contínua e acentuada no volume de água armazenada, sendo necessária a elaboração de termos de uso da água para disciplinar os locais com potencial conflito pelo baixo nível de água.

O Nordeste enfrenta sérios problemas quanto à distribuição e o consumo de água potável, são longos períodos de secas e má distribuição do recurso, mas, mesmo assim, os aspectos culturais, educacionais e a falta de consciência da população resulta no consumo exacerbado de água, indicando que há pouca preocupação por parte dos indivíduos quanto à realidade hídrica local. Por exemplo, o Piauí consome 143,74 I/hab/dia, e a Paraíba consome cerca de $130 \mathrm{l} / \mathrm{hab} /$ dia, sendo que o ideal, de acordo com a ONU, é que sejam consumidos no máximo 110 l/hab/dia (ARAÚJO et al., 2016).

O estudo de Silva et al. (2013) observou o desperdício de água ocasionado pelos aparelhos hidrossanitários dos banheiros de uma universidade da Paraíba, assim como os bebedouros. 0 resultado apresenta que são desperdiçados $453,27 \mathrm{~m}^{3} / \mathrm{mês}$, oriundo de falhas técnicas e humanas. Vale ressaltar que cerca de $2.057,8 \mathrm{~m}^{3} / \mathrm{s}$ da água retirada dos rios, lagos e demais fontes são destinadas para a irrigação e demais atividade econômicas do país (ANA, 2017). 
Em uma visão ampliada, os sistemas de abastecimento descentralizado eas inovações de reutilização de água estão se tornando alternativas viáveis no longo prazo, embora as questões orçamentárias, as barreiras regulatórias e a resistência ao comportamento reuso influenciem na adoção dessas práticas (KROZER et al., 2010; GIURCO et al., 2011; PINGALE; JAT; KHARE, 2014; MOSTAFAVI et al., 2018). A reutilização de água reduz as retiradas de sistemas de água doce e alivia o volume de águas residuais e nutrientes associados a cargas poluentes que são descarregadas em reservatórios de água doce (LEVINE; ASANO, 2004; DOLNICAR; HURLIMANN; GRÜN, 2012).

A importância da conservação da água tanto no manejo como no consumo tem sido objeto de discussão, tendo em vista que os consumidores domésticos tendem a desperdiçar água. Diversos estudos identificaram um conjunto de influências diretas e indiretas sobre o consumo de água que podem ser aplicadas para mudar o comportamento do uso da água dos consumidores e alcançar a conservação da água residencial, tais como os aspectos culturais, conscientização, gerenciamento do consumo residencial, sensibilização, captação e distribuição desregular dos recursos, por exemplo, vistos nos trabalhos de Araújo et al. (2016), Giurco et al. (2011), Silva et al. (2013), Mostafavi et al. (2018) e Lowe, Lynch e Lowe (2014). Tal discussão se torna ainda mais relevante no Brasil, dado as disparidades de oferta e de padrões de consumo de água, principalmente na região Nordeste. Assim, o desenvolvimento de estudos à luz do marketing social pelos órgãos governamentais é importante para a ativação de políticas públicas direcionadas a melhorar o bem-estar social.

Nestes termos, o objetivo deste artigo é discutir aspectos que influenciam a redução do desperdício e do consumo de água sob a perspectiva de marketing social. Para isto, a seguir são apresentadas as bases teóricas que nortearam a pesquisa, os procedimentos metodológicos adotados e os resultados provenientes da análise de conteúdo. Por fim, são expostas as considerações finais.

\section{MARKETING SOCIAL E O CONSUMO DE ÁGUA}

Os princípios norteadores das discussões clássicas em marketing social apresentados por Kotler e Zaltman (1971) referem-se aos esforços direcionados a influenciar comportamentos que promovam o bem-estar social. Nesse sentido, Lee e Kotler (2016) afirmam que o marketing social tem o objetivo de influenciar o público-alvo a aceitar um novo comportamento; rejeitar um comportamento potencialmente indesejável; modificar um comportamento atual; e abandonar um comportamento antigo e indesejável (LEE; KOTLER, 2016).

Em uma proposição mais moderna, Wood (2016) coloca que a tentativa de mudar comportamentos 
individuais, ignorando as bases socioeconômicas e ambientais subjacentes, é ineficaz. Em concordância com essa perspectiva, Almestahiri et al. (2017) afirmam que o marketing social precisa expandir a prática além da mudança de comportamento individual para garantir que os indivíduos direcionados não sejam estigmatizados dada a compreensão sobre o papel influente que o meio ambiente (social e construído) exerce sobre os indivíduos objetos da mudança.

Diante dessa constatação, observou-se que marketing social tem três níveis de influência - Upstream, Midstream e Downstream - e exige que várias partes interessadas trabalhem juntas em cada um desses níveis para oferecer uma gama de intervenções sociais (WOOD, 2016; BRENNAN; PREVITE; FRY, 2016; ALMESTAHIRI et al., 2017). O upstream é uma abordagem macro em que são analisadas as influências da cultura, do sistema econômico e das condições sociais para a formulação de políticas públicas e de leis que promovam a mudança social. O midstream se estende ao contato social mais aproximado como a família, a mídia de massa, os vizinhos e a educação, no sentido de criar um microssistema favorável às mudanças no comportamento individual. Por sua vez, o nível downstream é o mais tradicional objeto de pesquisa do marketing social por concentrar-se em comportamentos individuais específicos ou problemáticos em vez dos determinantes microambientes (que, por sua vez, são influenciados por fatores e interações sistemáticas mais amplas) (WYMER, 2011; WOOD, 2016).

Na esfera downstream, o marketing social é uma importante ferramenta para compreender o impacto do comportamento do consumidor em diversos problemas sociais, tendo em vista que, ao direcionar os sujeitos, as intervenções podem trazer benefícios diretos com as mudanças comportamentais (ALMESTAHIRI et al., 2017). Dadas as influências mais amplas exercidas sobre os indivíduos visando a mudança em suas atitudes, uma causa social que vem despertando o interesse dos estudiosos de marketing social é o consumo exacerbado e o desperdício da água potável (LOWE; LYNCH; LOWE, 2014; PHIPPS; BRACE-GOVAN; LOWE, 2011; RANDOLPH; TROY; LOWE, 2008; LAM, 1999).

Como estudado por Lowe, Lynch e Lowe (2014), os autores apresentaram sua contribuição do campo do marketing social ao ilustrar os principais impulsionadores da mudança comportamental voluntária quanto ao consumo da água, ressaltando as premissas do marketing social como fontes solucionadoras dos problemas sociais mais complexos e politicamente controversos. Dessa forma, assegurar o abastecimento de água a longo prazo requer o uso de abordagens pelo viés do ofertante (como a reciclagem de água) e do demandante (como a redução do desperdício). Diante da perspectiva downstream desse estudo, o comportamento de conservação torna-se objeto de análise para a redução do consumo de água (KANG et al., 2017), como será melhor discorrido na seção subsequente. 


\subsection{REDUÇÃO DO CONSUMO E DESPERDÍCIO DE ÁGUA POTÁVEL}

As constatações sobre o consumo de água no Brasil são preocupantes. Conforme relata a ANA (2017), o desperdício é um dos maiores problemas e as perdas se concentram na distribuição, com cerca de $20 \%$ a $60 \%$ da água tratada. Além dessa questão institucional, o consumidor também se destaca pelo uso descontrolado de água nas residências, desenvolvendo condutas problemáticas como, por exemplo, o tempo necessário para banho, o excesso de descargas no vaso sanitário, no uso da mangueira na limpeza das casas e na lavagem de carros, entre outras, como destacado no estudo de Marinoski et al. (2014), que indica o consumo de 0,13 L/s nos tanques e 0,17 L/s nas torneiras. Outro ponto que pode ser citado é o do consumo de água das famílias de até 3 salários mínimos, que gira em torno de 152 L/hab/dia, sendo o chuveiro considerado a maior fonte de desperdício de água com média de 36\% do consumo total, seguido do vaso sanitário com $29 \%$.

Algumas alternativas para combater o desperdício de água vêm sendo adotadas, como o incentivo ao uso de outras fontes de água, como água da chuva e águas residuais recicladas para fins não potáveis (DOLNICAR; HURLIMANN; GRÜN, 2012). Dias et al. (2018) identificaram, em seu estudo, que o uso da água da chuva como única fonte alternativa de água, nos prédios analisados, sem legislação local que determine a implantação obrigatória deste sistema, levou a um menor consumo de água potável. Corroborando com esses resultados, Grafton et al. (2009) determinaram que o consumo de água diminui quando a água da chuva é coletada e utilizada. A redução do consumo de água potável em virtude do uso da água da chuva também foi observada no estudo de Bailey et al. (2018), no mesmo estudo também foi identificada a necessidade de orientação para o armazenamento correto da água capitada.

O reajuste da tarifa de água é uma ferramenta importante para influenciar a redução do consumo e do desperdício de água. Nauges e Whittington (2017) identificaram, em seu estudo, que muitas empresas de serviços públicos cobram preços tão baixos da água que as famílias acreditam que não vale a pena pensar em ajustar o seu uso. No entanto, um desafio que os analistas enfrentam quando querem entender como as mudanças nas tarifas afetam as famílias pobres é que os registros de cobrança do cliente da empresa não incluem informações sobre a renda das famílias e outras características socioeconômicas e demográficas (FUENTE et al., 2016; NAUGES; WHITTINGTON, 2017; MARZANO et al., 2018).

As campanhas educacionais são outros instrumentos utilizados para combater o desperdício de água potável e desenvolver a conscientização dos cidadãos acerca da importância da preservação dos recursos hídricos (MAAS et al., 2017; KATZ et al., 2016; DOLNICAR; HURLIMANN; GRÜN, 2012; DUPONT; RENZETTI, 2013). A conscientização dos consumidores proporcionou novas oportunidades para os defensores da causa e para os gestores públicos para que pudessem incentivar práticas de consumo que 
reduzam o uso da água de forma mais facilitada, além de realizar ativamente programas abrangentes de conservação.

Conforme Cheung et al. (2009), o desperdício se relaciona com as perdas evitáveis, correspondendo à negligência do usuário que não tem consciência ambiental; em geral, o desperdício está associado ao comportamento de uso. Oliveira (2013) compreende que a redução do consumo de água considerado como desperdício resulta em economia e colabora para a conservação dos mananciais, na medida em que destaca a importância de estabelecer políticas públicas de incentivos ao uso racional da água que envolve ações tecnológicas e mudanças culturais para a conscientização da população quanto ao consumo. Vimeiro (2005) apresenta como exemplo de ação para a conscientização o Programa Água na Escola, desenvolvido pela organização não governamental (ONG) Água e Cidade. O programa conta com quatro projetos, os quais são a formação continuada de professores; a produção de material instrucional e institucional; visitas a laboratórios de pesquisa e estações de tratamento de água; e feiras específicas sobre água.

Outra iniciativa que buscou chamar atenção para os problemas relacionados à água e promover incentivo ao consumo racional da água foi a Campanha da Fraternidade lançada pela Conferência Nacional dos Bispos do Brasil - CNBB - no ano de 2004, que teve como tema a água e como lema "Água, fonte de vida". A abordagem objetivou fortalecer a reivindicação do acesso a esse recurso como um direito do indivíduo e difundir a necessidade da preservação e do uso racional dos recursos hídricos (VIMEIRO, 2005).

Além das ações promovidas por ONGs e entidades sociais, existem práticas de caráter doméstico que visam reduzir o consumo de água potável, o reúso é uma dessas práticas e caracteriza-se como processo de utilização da água por mais de uma vez, tratada ou não, para o mesmo ou outro fim (MOTA; MANZANARES; SILVA, 2006). A reutilização das águas, em geral, ocorre em atividades que não necessitam de água potável, como para o uso na descarga do banheiro e na rega do jardim, além da lavagem de pisos e veículos (LEMOS; FAGUNDES; SCHERER, 2009; PAES et al., 2010).

Por outro lado, os indivíduos que sofrem com escassez de água ocasionada pela seca, por dificuldade de acesso ou contexto social, realizam mais ações de combate ao desperdício da água no contexto domiciliar, além de fazerem a coleta de água da chuva e armazenarem em baldes, potes e tonéis, sendo essa água, na maioria das vezes, utilizada para o uso de práticas de higiene pessoal da família, além das atividades domésticas, como lavar roupas e louças, conforme apresentado nos estudos de Rozzoline e Gunther (2008), Lemos, Fagundes e Scherer (2011) e Santos, Araújo e Monteiro (2012). Tais elementos teóricos nortearam a prospecção empírica sobre o consumo e desperdício de água. 


\section{MÉTODO}

O objetivo deste tópico consiste em descrever os processos metodológicos adotados na pesquisa, com a intenção de analisar os fatores que influenciam as práticas do consumo consciente de água. Desse modo, foi realizada uma pesquisa qualitativa de caráter exploratório, tendo em vista a necessidade de entender como o consumidor gerencia o consumo de água (DENZIN; LINCOLN, 2006; VIEIRA; ZOUAIN, 2005). Como técnica de coleta de dados, foi utilizada a entrevista como melhor estratégia para identificar como as pessoas julgam o consumo de água, assim como as práticas de desperdício e a conscientização para um consumo regular, através de questões relativas ao próprio consumo de água, à consciência sobre o consumo e às ações corretivas que são adotadas. Foi utilizado um roteiro semiestruturado para guiar as entrevistas (ALVES, 2007; DUARTE, 2004).

O roteiro desenvolvido para as entrevistas foi elaborado com questões adaptadas e traduzidas do trabalho de Lowe, Lynch e Lowe (2014), tendo em vista que o estudo deles é o mais adequado ao objetivo do presente estudo, já que buscaram examinar como fatores comportamentais influenciam a redução do uso da água doméstica. O roteiro era formado por 6 questões para identificação do perfil dos voluntários e 22 questões divididas entre 3 tópicos, o primeiro tratou do consumo de água; o segundo sobre aspectos climáticos, a consciência sobre o consumo e o desperdício de água potável; o terceiro consistia em identificar as ações corretivas do consumo de água desregular, assim como a influência de canais informativos para a conscientização da população.

O acesso aos entrevistados se deu através da técnica "bola de neve", a qual consiste em capturar os sujeitos participantes da amostra através de amigos, parentes, contatos pessoais e conhecidos que facilitam a abertura do pesquisador ao espaço (ALVES, 2007). A pesquisa foi realizada com 35 indivíduos residentes no Nordeste brasileiro, com idades entre 24 e 55 anos, responsáveis pela manutenção do lar e pelo controle do consumo da água na residência. A realização das entrevistas tivera início no dia 04/11/2017 e encerrou-se no dia 06/01/2018; as gravações de áudio têm duração total de 9 horas e 39 minutos. Após a transcrição das entrevistas, foram obtidas 107 laudas com fonte Times New Roman, tamanho 11 e com espaçamentos simples.

Com relação à análise de dados, foi realizado o procedimento de transcrição das entrevistas. Em sequência, o processo de análise de conteúdo foi desenvolvido com base nas interpretações das respostas obtidas através das entrevistas, para em seguida criar subcategorias e códigos a partir das categorias abertas, definidas durante o andamento do estudo (LAVILLE; DIONE, 1999). Sendo definidas as cinco dimensões: consumo diário; consumo do grupo de referência; consciência sobre o consumo; reciclagem da água; e análise de marketing social. O que resultou em cinco categorias: não pode desperdiçar água; é muita 
água; quanto mais preservar, melhor; eu reaproveito essa água; e se não aprende pela conscientização, aprende com multa.

\section{ANÁLISE DOS RESULTADOS}

Neste tópico são apresentados os resultados obtidos na análise de conteúdo das entrevistas, as seções seguintes expõem a relação entre as dimensões e categorias geradas.

\subsection{NÃO PODE DESPERDIÇAR ÁGUA}

O primeiro tópico mostra as discussões a respeito do consumo diário de água potável e qual a finalidade dada à água pelos indivíduos entrevistados. O perfil encontrado durante as entrevistas mostra que os indivíduos voluntários participantes são pessoas cujo o grau de instrução varia entre o ensino médio completo e o superior completo, sendo responsáveis pela manutenção da higiene do lar, do controle do consumo de água e da renda familiar. Ao indagar os indivíduos a respeito do consumo de água potável observou-se que o uso diário se resume nas necessidades fisiológicas, tais como beber e usar a água para o cozimento dos alimentos e às atividades básicas de manutenção de higiene pessoal e do lar.

Uma das formas de consumo de água é através da higienização da calçada, quintal e dos veículos dos indivíduos, percebeu-se que são poucos os que exercem algum controle nesse consumo. Por outro lado, os entrevistados mencionaram que utilizam estratégias para higienizar os locais abertos, como: varrer, usar baldes em vez de mangueiras, fazer o uso de cisternas, reaproveitar água para limpar em vez de abusar da água potável.

"A calçada eu só varro. Já o carro eu mando lavar no lava-jato." (E.9).

"A calçada é uma vez por semana com água reaproveitada da lavagem de roupa e o carro a gente manda lavar fora." (E.19).

Alguns relatos mostraram que ainda existem pessoas que utilizam mangueiras e água corrente para limpar calçadões e carros, além de considerar o tempo de uso como algo rápido: "O carro é lavado na 
mangueira, gasto pouco tempo, algo em torno de 40 minutos" (E.34). Tais fatos se assemelham com os resultados apresentados pelas pesquisas da Agência Nacional das Águas (2017).

Quanto às práticas do consumo para higiene pessoal, percebeu-se que os indivíduos optam por banhos curtos e em números maiores durante o dia, girando em torno de 3 banhos diários com duração de 5 a 15 minutos, assim como a higienização bucal, porém, buscando sempre controlar o gasto de água ao manter a torneira e o chuveiro ligados.

"Eu tomo banho rápido, já pela questão da água e escovando os dentes também, pouca água em um copo, de preferência, nunca a gente escova na torneira." (E.20).

"Para tomar banho acho que uns 15 minutos. Do mesmo jeito é quando vou fazer as outras coisas, sempre fecho a torneira, não pode desperdiçar água não!" (E.1).

Com relação ao uso da água potável para as descargas, os indivíduos relataram que utilizam ao menos 6 vezes por dia. Alguns entrevistados sugeriram a utilização de pequenos baldes ou a prática de reaproveitar a água da roupa lavada para esse fim.

\section{2 É MUITA ÁGUA!}

Este tópico tem o objetivo de mostrar o julgamento que os entrevistados têm sobre o consumo de água dos seus familiares, vizinhos e colegas de trabalho. De acordo com os entrevistados, os indivíduos avaliam que as pessoas com mais idade apresentam maior preocupação quanto ao consumo, buscam economizar e regular constantemente. Por sua vez, os jovens são caracterizados pelo fato de fazer uso desnecessário da água, ao demandar tempo demais no banho, além de lavar os veículos com maior frequência.

Outro ponto quedeveser levado emconsideraçãoéa questão climática daregiãoe, consequentemente, o impacto nas práticas relacionadas ao consumo. Nas cidades cuja escassez da água se faz mais presente, observou-se que há maior preocupação e mais responsabilidade quanto ao desperdício e o consumo. Além disso, nesses lugares, a lição do valor da água é repassada de geração para geração, como pode ser visto nos relatos: "Tenho esse cuidado desde criança ensinado pelos meus pais" (E.3); e "As minhas filhas também economizam bastante, elas sempre me viram economizando e cresceram assim" (E.29). 


\section{Gestãoe \\ Desenvolvimento}

Por outro lado, os residentes em locais que são abundantes em água possuem a prática de gastar em demasia, sem se preocupar com as consequências vindas desse comportamento. De acordo com os relatos, essas pessoas têm o hábito de lavar calçadas e carros com água corrente, utilizando mangueiras.

"Lavando carro e calçada com mangueira. É o que eu vejo aqui que eles fazem." (E.5).

"O consumo deles é muito alto, eu acho que é um desperdício muito grande." (E.17).

\subsection{QUANTO MAIS PRESERVAR, MELHOR!}

No terceiro tópico, o intuito foi apresentar a discussão sobre a consciência dos indivíduos quanto ao consumo, o desperdício e a preservação da água, assim como as suas práticas diante de cada tema. Diante dos resultados obtidos, foi percebido que a maioria dos entrevistados acreditam que a consciência para questões relacionadas aos problemas sociais, como o consumo excessivo da água, parte da educação, da cultura e da empatia. Afirmaram que se deve economizar água pelo fato de que é um recurso natural e que pode ser limitado devido à falta de consciência das pessoas.

"Eu acho que a gente deveria preservar mais a água, ela pode acabar e as futuras gerações sofrerão, acho louvável reduzir o consumo e sermos conscientes." (E.34).

"Quanto mais preservar, melhor! Se a gente ficar sem água vai ser pior." (E.1).

"A gente precisa se reeducar, se conscientizar." (E.24).

Os resultados mostraram que os entrevistados acreditam que o desperdício é algo que deva ser evitado, tendo em vista que a água pode acabar e todos sairão prejudicados. Além disso, julgam como irracionais os seres que não possuem consciência desse excesso e desperdício, principalmente para a região que possui um histórico de escassez de água. Para eles, a consciência surge a partir do momento em que o indivíduo decide se policiar. 
"Quando você começa a cobrar de si mesmo uma postura, você fica desconfortável em relação ao comportamento e a atitude do outro. Se um dia você for prejudicado, você vai ter a consciência de que: 'Eu fiz a minha parte."' (E.24).

O princípio dessa decisão de redução do consumo é oriundo das reflexões e da educação individual. A prática de economizar deve ser algo intrínseco, as pessoas devem reconhecer que a existência da água no presente não garante a existência no futuro e, com isso, as futuras gerações e os próprios indivíduos sofrerão com a falta d'água. De modo que muitos indivíduos julgam como obrigação economizar a água, ao considerar que "cada vez mais não tem de onde tirar água, porque não tem programa para seca, e com essa mudança climática a nossa região fica a cada dia pior". (E.28).

Com isso, pode-se ver que as pessoas têm consciência do gasto demasiado da água, principalmente aquelas que já sofreram com períodos de escassez e racionamentos, além de associarem o mal comportamento com o poder aquisitivo, no sentido de que muitos que possuem melhores condições financeiras acreditam que podem gastar mais água.

"Ainda vejo muito esse desperdício, vejo muito essa cultura do poder pagar e posso desperdiçar." (E.25).

"Ou economiza ou você fica sem!" (E.30).

Muitos dos entrevistados relataram como faziam para sobreviver com pouquíssima água: "A gente já sofreu, a gente viu o quanto é difícil ficar sem água" (E.11). Essas pessoas tiveram que criar reservatórios caseiros com baldes, panelas e garrafas, adaptando a rotina ao mínimo de água possível, tendo que enfrentar longos dias com pouquíssima água. Partindo desse raciocínio surge o seguinte subtópico.

\subsection{EU REAPROVEITO ESSA ÁGUA}

Neste tópico é discutida a questão do reaproveitamento de água. Ao questioná-los sobre a reciclagem de águas residuais, obteve-se que os indivíduos possuem a prática de aproveitar a água para outros fins, 
por exemplo, a água que lavam a roupa utilizam para limpar o quintal e a calçada, ou a água do banho das crianças que pode se reaproveitada para dar descargas ou limpar a área dos animais domésticos, evitando o uso de água potável.

"Eu reaproveito essa água para lavar calçada, para lavar quintal." (E.29).

"Não estamos falando de coisas impossíveis ou de coisas futuristas, já existem projetos usando a tecnologia, para aproveitar essa água." (E.24).

Outro ponto levantado pelos entrevistados trata-se da captação e reutilização da água da chuva, como estratégia para reduzir o consumo de água potável. Eles afirmaram que, dependendo da forma que é coletada e tratada, é possível utilizá-la para beber e cozinhar, ou para higiene corporal e do lar. Para esses indivíduos, o reaproveitamento da água da chuva seria maior se houvesse informações sobre a forma ideal para o tratamento. Esse resultado está de acordo com os estudos de Dolnicar, Hurlimann e Grün, 2012; Bailey et al. (2018) e Grafton et al. (2009), que apresentam formas simples e acessiveis de reaproveitar a água da chuva, como forma de ajudar o meio ambiente e o bolso do consumidor.

"A gente usa muita água da chuva até para beber, a gente junta no quintal, tem uns baldes e a gente enche, depois filtra, trata, ferve e usa normalmente para qualquer coisa dentro de casa." (E.15).

De acordo com os entrevistados, mais importante que reaproveitá-la é reduzir o gasto, ser consciente e econômico, buscando sempre se fiscalizar e direcionar o uso de forma correta, evitando o uso desnecessário: "Se cada um fizer a sua parte economizando, a gente chega lá" (E.20). Como visto, ao reaproveitar a água, o indivíduo tanto reduz o consumo quanto consegue reduzir os gastos com o pagamento de água encanada, o que introduz o tópico seguinte, que tratará de aspectos econômicos e punitivos versus o consumo de água e conscientização. 


\subsection{SE NÃO APRENDE PELA CONSCIENTIZAÇÃO, APRENDE COM MULTA}

Neste tópico são discutidas as campanhas de marketing social sobre o consumo e desperdício da água, assim como a influência para a adoção de práticas positivas. De acordo com os respondentes, não existem incentivos diretos por parte de órgãos públicos ou privados para a redução do consumo de água, portanto, os canais de informações não possuem suporte para divulgações desse cunho.

Como visto no referencial teórico, a região Nordeste apresenta características próprias quanto à distribuição e ao consumo de água, comparada com a realidade do país. A distribuição de água é bastante desregular, alguns pontos passam por extrema escassez de água, o índice do atendimento total de água chega a apenas $72,9 \%$ do que deveria ser ofertado (ARAÚJO et al., 2016) e a água ofertada pode ser considerada insuficiente e mal distribuída (ANA, 2017). Além disso, a cultura local, a falta de conhecimento, o contexto social e outros fatores acabam interferindo no consumo consciente (ARAÚjO et al., 2016; MARINOSKI, et al., 2014; VIMEIRO, 2005; LEMOS; FAGUNDES; SCHERER, 2011).

Dessa forma, ao considerar esse contexto, nota-se a necessidade de haver ações mais orientadas para a realidade local e individual, considerando os aspectos do marketing social cuidadosamente projetados para expandir a participação da sociedade em ideias conscientes, fazendo com que mudem seus comportamentos de forma positiva (LOWE; LYNCH; LOWE, 2014). Tal adequação se torna necessária para atender às demandas locais, cabendo aos governantes traçarem estratégias capazes de atingir a população para que seja minimizado o desperdício de água e aumentado o conceito de reaproveitamento, não deixando que essas iniciativas se limitem a grupos restritos, como foi achado na presente pesquisa e relatado a seguir.

Apenas pequenas escolas, igrejas e associações possuem a iniciativa de disseminar - através de panfletos, contato "porta-a-porta" e mutirões - o conhecimento a respeito de práticas positivas com o intuito de criar a cultura da economia e da preservação dos recursos naturais. E mais, eles afirmaram a importância de educar as crianças sobre esses hábitos, tendo em vista que estas podem adotar comportamentos positivos mais facilmente que os adultos, além de poder compartilhar o conhecimento com os que os cercam.

"Eu só tenho conhecimento da escola da minha filha, lá eles têm o dia da água e nesse dia eles ensinam as crianças a economizar. Ela adotou um balde de $5 \mathrm{~L}$ e consegue tomar banho duas vezes com essa água." (E.14).

"A igreja é a única instituição aqui que se movimentou a respeito disso." (E.29). 
Os entrevistados acreditam que a educação e o repasse de informações são as chaves para a mudança, só assim as pessoas passariam a se policiar e a evitar desperdícios. As ações necessárias consistem em distribuir panfletos informativos, realizar palestras, utilizar os meios de comunicação, tais como rádio, televisão, redes sociais, para alertar a população acerca dos hábitos de consumo da água, assim como as alternativas para economizar e reutilizar.

Outro ponto levantado é o fato de que a própria fornecedora de água deveria adotar um comportamento positivo e repassar as informações para a sociedade, juntamente com agentes sociais. As campanhas serviriam para conscientizar as pessoas e para reciclar as ideias constantemente.

"Tudo parte da educação, se a gente instigar os órgãos governamentais e cobrar isso das escolas, dos gestores, as crianças ficarão motivadas, juntamente com os pais, é um ciclo." (E.33).

"É importante o repasse para as crianças, porque elas passam cobrar os adultos e levam o conhecimento para sempre." (E.13).

"A principal coisa é alertar sobre a gravidade da situação, mas não só na teoria, mas sim apresentar caminhos práticos e concretos." (E.35).

Os entrevistados foram questionados a respeito da conexão entre o aumento nas tarifas cobradas, os racionamentos e os hábitos de economia de água. Os resultados obtidos mostraram que o fato de aumentar o preço pago pelo consumo influencia na redução do consumo, exceto para aqueles que possuem renda financeira superior, pois há a crença de que se podem pagar, podem consumir sem demais preocupações. Quanto ao racionamento, há influência no sentindo de que altera a rotina diária devido a falta d'água, com isso, o consumo passa a ser menor e o costume pode ser perpetuado. Além disso, os indivíduos acreditam que quem consome em excesso, como os que lavam calçadas e carros com mangueira, devam pagar um valor adicional como forma de punição pelo mal comportamento. 
"Quem gasta mais tem que pagar mais, mas deveriam se conscientizar e não gastar tanto. Não é porque pode pagar mais caro que vai gastar mais água, isso não dá o direito." (E.1).

"Se não aprende pela conscientização, aprende com multa." (E.9).

Outras punições citadas pelos entrevistados baseiam-se no nível reduzido da taxa da água, para que aprendam a viver com recursos limitados, além de ter a obrigação de pagar com serviços sociais para que possam se humanizar e pensar nos demais seres. Mas essas ações só seriam válidas após campanhas informativas para que as pessoas detivessem conhecimento das práticas corretas.

\footnotetext{
"Tenho que ter a consciência que lá na frente isso vai me faltar e o dinheiro não é suficiente, não vou beber dinheiro, entende?!" (E.10).

"Essas pessoas que gastam demais deveriam ir para lugares onde a água é escassa para prestarem serviços sociais, pensando na possibilidade de serem mais empáticos, têm que ver o que eles possuem e desperdiçam. Não é porque eu tenho dinheiro para pagar qualquer valor que vou usar indevidamente." (E.15).
}

Ao questioná-los sobre o que os faria reduzir o consumo de água, percebeu-se que medidas mais citadas são o aumento no valor da tarifa, informar sobre o risco de faltar água, promover uma reeducação ambiental de modo a influenciar na própria cultura e na consciência dos envolvidos, além de empregar incentivos como premiações e reconhecimentos desenvolvidos pelos órgãos públicos em parceria com as empresas fornecedoras de água.

\section{DISCUSSÃO DOS RESULTADOS}

A partir dos resultados obtidos na análise das cinco dimensões abordadas no presente estudo, pode-se chegar à conclusão de que o comportamento do público entrevistado se diferencia de acordo com o contexto social, cultural, local, ambiental e financeiro no qual se encontram inseridos. Os resultados 
demonstram que pessoas que residem em lugares que apresentam escassez de água possuem maior tendência a economizar e destinar mais corretamente a água utilizada. Além disso, o fator econômico interfere, pois, geralmente, são pessoas com poder aquisitivo mais baixo e, consequentemente, buscam reduzir o consumo com o intuito de reduzir os custos.

Traçando um paralelo entre as questões emergentes na análise e os estudos de Wood (2016), Almestahiri et al. (2017) e Brennan, Previte e Fry (2016), que demonstram a importância de adotar a nova perspectiva do marketing social, foi evidente a necessidade de considerar o contexto que o indivíduo se encontra. Nesse sentido, no nível upstream os entrevistados demonstraram acreditar no poder de influência da educação para transformar o comportamento e estimular a consciência do consumo de água potável; e mais, foram capazes de indicar sugestões sobre as melhores formas de repassar as informações a respeito e gerar conhecimento de forma a beneficiar toda a sociedade, indo ao encontro dos relatos dos seguintes autores: Maas et al. (2017), Katz et al. (2016), Dolnicar, Hurlimann e Grün (2012), Dupont e Renzetti (2013) e Vimeiro (2005). As ações indicadas apontam a distribuição de panfletos e a utilização dos meios de comunicação (televisão, rádios, redes sociais) como possíveis instrumentos de disseminação do conhecimento.

Outro ponto levantado pelos entrevistados ainda no nível upstream trata do reajuste da tarifa de água que, para Nauges e Whittington (2017), é uma ferramenta importante para influenciar o consumo consciente, reduzindo o desperdício de água. Em um dos seus estudos, os autores identificaram que os preços cobrados por certas empresas são baixos e por isso pouco influenciam a redução. Essa questão, em até certo ponto, condiz com os resultados obtidos, pois os indivíduos acreditam que quando envolvem questões financeiras as pessoas tendem a economizar o consumo pensando na tarifa que terão que pagar. Por outro lado, acreditam que os que possuem renda superior não se preocuparão com o consumo, já que o valor será irrisório, como o caso citado por Nauges e Whittington (2017).

Outros dois pontos importantes são acrescentados no aspecto econômico como influenciador do consumo de água potável. Inicialmente, é preciso considerar que, ao se cobrar taxas de consumo a mais, deveria ser levado em consideração o contexto social do indivíduo, seu grau de instrução, sua renda, sua localização, para poder incluí-lo ou não ao grupo seleto de pagadores de taxas a mais pelo consumo (FUENTE et al., 2016; NAUGES; WHITTINGTON, 2017; MARZANO et al., 2018). Em segundo lugar, o fato de que os entrevistados acreditam que, tanto para pessoas menos favorecidas economicamente quanto para as mais favorecidas, a melhor punição e alerta sobre o consumo seria o corte provisório (racionamento) da água, para que possam vivenciar experiências com limitações e escassez como forma prática de aprendizagem. 
O nível midstream diz respeito ao contato social mais aproximado que o indivíduo tem, sendo levantados questionamentos a respeito dos grupos que os indivíduos estavam inseridos e a sua influência sobre o consumo de água. Os resultados mostraram que existem duas faces enquanto grupo e indivíduo, pode-se citar o exemplo da entrevistada (E.29) que diz que seus pais vieram de um lugar com escassez de água e que o costume era economizar e ter cautela, com isso, a entrevistada passou a ensinar seus filhos a realizar um consumo mais consciente.

Por outro lado, tendo em vista as duas vertentes que podem ser abordadas no nivel midstream, os entrevistados foram capazes de julgar o consumo dos indivíduos mais próximos, apontando que alguns familiares, colegas de trabalho e vizinhos costumam utilizar água de forma desregular e desnecessária. Além disso, ao julgar seus grupos, os relatos indicam que as pessoas com maiores idades são mais preocupadas que os jovens que já nasceram economicamente em abundância.

No nivel downstream, os resultados apontam que a consciência e o comportamento derivam de fatores relacionados à situação econômica, à cultura e ao local de residência, se é uma área escassa ou não, se já enfrentaram períodos de racionamento ou se ao menos possuem vínculo com alguém que já tenha passado por essa experiência.

Dessa forma, as pessoas que residem em lugares com fluxo de água favorável possuem o hábito de utilizar água abundante para lavar calçadas e automóveis com maior frequência, além de demonstrarem maior consumo durante os banhos e o uso excessivo de descargas no vaso sanitário, esses resultados estão compatíveis ao retratado pela Agência Nacional de Águas (2017). Ainda nesse nível, questões a respeito da consciência do consumo de água foram abordadas, as reflexões sobre o consumo apresentam que esses comportamentos são espelhos da educação do indivíduo, das suas crenças, da sua capacidade de empatia e do reconhecimento dos limites do consumo e das suas reais necessidades; ao pensar nas gerações futuras, o comportamento tende a direcionar para a economia da água, pois não querem privar seus descendentes da utilização e do benefício de ter água potável.

Partindo desse raciocínio, os resultados apontam práticas como a criação de reservatórios caseiros, utilizando baldes, panelas e até mesmo garrafas PET para armazenar água, buscando adequar a rotina à quantia de água existente, identificando as prioridades e utilizando conforme a real necessidade. Além dessas estratégias, pode-se constatar a existência de técnicas reconhecidas e utilizadas para auxiliar no consumo consciente, tais como buscar varrer calçadas e quintais em vez de utilizar mangueiras e lavar com água corrente; ao higienizar os automóveis, controlar o consumo com baldes pequenos de água, além de reaproveitar e reciclar a água para outros fins; como o exemplo mais citado, utilizar a água da lavagem de roupas para higienizar calçadas ou dar descargas. Vale ressaltar que alguns dos entrevistados, que 
residem em locais com poucos recursos hídricos, já possuem o hábito de realizar essas estratégias como forma de economizar e garantir que terão água posteriormente, como indicam os estudos de Dolnicar, Hurlimann e Grür (2012).

Outra estratégia alternativa utilizada para a diminuição do consumo de água potável é o reaproveitamento de água da chuva. Achados como os de Dias et al. (2018), Grafton et al. (2009), Lemos, Fagundes e Scherer (2011) e Bailey et al. (2018) colaboram com essa afirmação, pois indicam que, ao utilizar a água da chuva, o consumo de água potável é reduzido paralelamente. Embora os autores indiquem e tenha sido comprovado com a presente pesquisa, ainda é necessário a orientação da forma de captação, armazenamento e melhor utilização da água da chuva, pois muitos dos relatos mostram que os entrevistados não fazem tal prática por falta de conhecimento.

Levando em consideração que o conhecimento deriva da educação e do repasse de informações, cabem questionamentos a respeito do que o nivel upstream tem feito para colaborar com as práticas positivas de consumo de água potável. Foi percebido durante as entrevistas que o próprio público reconhece a necessidade de realizar alguma ação de forma reguladora ou que cause incentivos para minimizar o consumo de água, tendo em vista que eles acreditam que a inserção de taxas cobradas devido ao consumo excessivo possa ser eficaz, levando em consideração que as pessoas são movidas, principalmente, por fatores econômicos, além da criação de punições mais severas para aqueles que possuem renda superior, pois nesses casos o dinheiro não surtiria tanto efeito.

Entretanto, ressaltam a necessidade de trazer incentivos à população para que possam alcançar a mudança comportamental. Muitos exemplos são citados como: gratificações, reconhecimentos simbólicos e descontos. Vale frisar que, independentemente de incentivos ou punições, a população enfatizou que a implementação de tais estratégias deveria prezar pelas classes sociais, pois seria injusto cobrar uma taxa exorbitante a alguém com renda inferior a 1 salário mínimo e com ' $n$ ' filhos, e seria ineficiente cobrar taxas pequenas a pessoas com renda elevada. Ou seja, é preciso que haja uma regulação eficiente por parte dos envolvidos no nível upstream para que mude o comportamento do nível downstream.

De maneira geral, a presente pesquisa indica que as iniciativas de conscientização derivam de ações de alguns grupos preocupados com o consumo e com o futuro da população, por exemplo, algumas escolas, igrejas e associações que tiveram essa iniciativa de buscar meios de conscientizar as pessoas, realizando diversas estratégias, como mutirões que distribuem materiais educativos e dialogam com a população em busca de explicar a importância de práticas positivas.

As escolas, por sua vez, realizam palestras, dinâmicas com as crianças e seus pais em busca de incentivar a preservação. De acordo com os entrevistados que possuem filhos, as crianças devem receber maiores ações de conscientização e educação em todos os aspectos, como aponta Vimeiro (2005). 
Ademais, os estudos de Lee e Kotler (2016), Wood (2016), Almestahiri et al. (2017) e Brennan, Previte e Fry (2016) indicam que o marketing social tem o objetivo de influenciar os indivíduos a adotar um comportamento novo que trará resultados satisfatórios e benéficos, assim, se houver utilização correta das ferramentas do marketing social, o governo, juntamente, com o suporte de instituiç̧̃̃es privadas ou sociais e com a aceitação e apoio da população, poderá criar mecanismos capazes de gerar consciência e reduzir o consumo de água, colaborando com um comportamento de consumo consciente e sustentável, como relatam os estudos de Maas et al. (2017), Katz et al. (2016), Dolnicar, Hurlimann e Grün (2012) e Dupont e Renzetti (2013).

Como pode ser visto, a mudança não se centra no governo ou no próprio indivíduo, é preciso que haja metas e objetivos claros, transparentes e comuns, criando o sentimento de autoridade e de pertencer à sociedade em todos os atores envolvidos (governo, empresas e população), para que o comportamento possa seguir uma linha única, a partir disso, a população seria capaz de reduzir o consumo de água visando causar o bem-estar e melhorias sociais, levando em consideração que teriam conhecimento sobre os danos do comportamento negativo, tais como problemas ambientais, sociais e econômicos.

\section{CONSIDERAÇÕES FINAIS}

O presente estudo identificou que a água potável é utilizada, prioritariamente, para suprir as necessidades fisiológicas, higiênicas e na realização das atividades domésticas. As principais utilidades apresentadas pelos entrevistados foram: cozinhar e beber, higiene corporal e bucal, lavar louça, roupa e a limpeza do lar. Um fato relevante observado no comportamento dos entrevistados é a prática de ações voltadas para a redução do consumo da água, tais como: reutilização da água oriunda da lavagem de roupa, varrer a calçada, ao invés de lavar com água corrente, e tomar banhos rápidos, além do uso e armazenamento da água da chuva, principalmente nas regiões que apresentam escassez de água e períodos de maior estiagem provocados pela seca.

Observou-se também que os entrevistados julgam o consumo dos jovens superior ao consumo das pessoas com mais idade. Além disso, os resultados apontam que o consumo excessivo e o desperdício têm relação direta com o poder aquisitivo. Corroborando com os estudos de Dias et al. (2018) que identificaram que o aumento do consumo de água pode estar relacionado ao poder de compra da população, as autoras também observaram que o consumo de água doméstico é maior em edifícios residenciais com valores monetários mais altos, tendo em vista que tais edifícios contam com uma área construída maior, resultando em maior consumo de água. No entanto, o estudo de Nauges e Whittington (2017) aponta 
que existem muitas famílias ricas que usam pequenas quantidades de água e muitas famílias pobres que usam grandes quantidades de água.

Esta disparidade entre os resultados dos estudos pode estar relacionada com a consciência do consumidor em relação ao uso da água. Dessa forma, a presente pesquisa aponta que a formação da consciência recebe influência da cultura, mas que pode ser desenvolvida por meio da educação. Não foram citadas, nesse estudo, ações ou iniciativas por parte de órgãos públicos para a redução do consumo de água, as poucas iniciativas que foram apontadas tinham o foco na educação e foram realizadas por escolas, igrejas e associações. Os resultados também mostraram que o aumento das tarifas influencia positivamente na redução do consumo de água.

Em complementaridade, os resultados apresentados por Katz et al. (2016) implicam que o aumento de preço pode ser eficaz para a redução do consumo de água, porém com pouco efeito no longo prazo. Por outro lado, as campanhas de conservação podem ser tão efetivas e ter efeito de longo prazo. Isso sugere que o uso de campanhas pode ser implementado de forma mais efetiva em situações em que os decisores e formuladores de políticas públicas precisam lidar com escassez e a provisão de água relativamente curta, como as que ocorrem durante a seca.

Seguindo os pressupostos apresentados anteriormente sobre a atuação do marketing social na esfera downstream para combater um comportamento indesejável na sociedade, aconselha-se, para o problema da água, que sejam disponibilizadas informações corretas nas mídias de massa (rádio, televisão e redes sociais), sobre consumo e o desperdício de água, além de orientações em linguagem acessível e compreensivel para o público acerca das formas corretas de fazer a reciclagem de águas residuais e o armazenamento de água da chuva.

Sugere-se, também, que sejam implantadas estratégias voltadas para minimizar os efeitos das condições favoráveis ao desperdício de água potável, como o desenvolvimento de aplicativos para celulares no qual se possa fazer denúncias de vazamentos de água ou de exagero no uso (lavagem de carros, calçadas, muros, entre outros); distribuição de material de cunho educativo e informativo por parte das agências que entregam o serviço de águas e esgoto; e aplicação de multas em casos recorrentes.

Por fim, pode-se realizar atuações diretas com os consumidores/cidadãos, o poder público pode trabalhar em conjunto com algumas instituições públicas e as diversas entidades da sociedade civil para ofertar palestras e oficinas, com o intuito de desenvolver conhecimento teórico e prático sobre a preservação e reutilização da água, além de ações de formação técnicas sobre a coleta e armazenamento da água da chuva. Vale ressaltar que o processo de educação e conscientização deve atingir também as crianças, e a escola é um ambiente propício para esse tipo de ação. 
Quanto às limitações da presente pesquisa, destacam-se o acesso restrito aos participantes por questões econômicas e por aceitação da população, que acreditavam que a presente pesquisa estava sendo conduzida pela empresa distribuidora de água dos locais abordados. Cabe ressaltar que os que se dispuseram a responder compreenderam o viés acadêmico e o objetivo de contribuir com o marco teórico do marketing social. Como sugestões para pesquisas futuras, deixamos a ideia de realizar pesquisa quantitativa que possa ser compartilhada com um grupo maior de respondentes, buscando atingir o Nordeste todo ou até mesmo outras regiões do País. Além disso, seria interessante realizar um estudo com o governo, identificando a percepção que eles têm quanto à temática, quais são as estratégias adotadas e como são realizadas.

\section{REFERÊNCIAS}

(ANA), Agencia Nacional das Águas. Conjuntura dos recursos hídricos no Brasil 2017: Relatório Pleno. Brasilia: Ana, 2017. 169 p. 9.

ALMESTAHIRI, Ra'd et al. The Use of the Major Components of Social Marketing. Social Marketing Quarterly, [s.I.], v. 23, n. 3, p.232-248, 18 abr. 2017.

ALVES, Magna. Como escrever teses e monografias: um roteiro passo a passo. Rio de Janeiro:

Elsevier, 2007. P.65.

ARAÚJO, S. C. et al. Distribuição espacial de indicadores operacionais de serviço de abastecimento de água no Nordeste Brasileiro. Revista Verde de Agroecologia e Desenvolvimento Sustentável, [s.l.], v. 11, n. 1, p.20, 27 set. 2016. Grupo Verde de Agroecologia e Abelhas. http://dx.doi.org/10.18378/rvads. v11i1.4470.

BAILEY, Ryan T. et al. Sustainability of rainwater catchment systems for small island communities. Journal Of Hydrology, [s...], v. 557, p.137-146, fev. 2018.

BRENNAN, Linda; PREVITE, Josephine; FRY, Marie-louise. Social marketing's consumer myopia. Journal Of Social Marketing, [s.I.], v. 6, n. 3, p.219-239, 11 jul. 2016.

DENZIN, N. K. e LINCOLN, Y. S. Introdução: a disciplina e a prática da pesquisa qualitativa. In:

DENZIN, N. K. e LINCOLN, Y. S. (Orgs.). O planejamento da pesquisa qualitativa: teorias e abordagens. 2. ed. Porto Alegre: Artmed, 2006. p. 15-41. 
DIAS, Talita Flores; KALBUSCH, Andreza; HENNING, Elisa. Factors Influencing Water Consumption in Buildings in Southern Brazil. Journal Of Cleaner Production, [s.I.], p.1-19, fev. 2018.

DOLNICAR, Sara; HURLIMANN, Anna; GRÜN, Bettina. Water conservation behavior in Australia. Journal Of Environmental Management, [s.I.], v. 105, p.44-52, ago. 2012.

DUARTE, R. Entrevistas em pesquisas qualitativas. Educar, Curitiba, n. 24, p. 213-225, 2004.

DUPONT, Diane P.; RENZETTI, Steven. Household behavior related to water conservation. Water Resources And Economics, [s.I.], v. 4, p.22-37, dez. 2013.

FUENTE, David et al. Water and sanitation service delivery, pricing, and the poor: An empirical estimate of subsidy incidence in Nairobi, Kenya. Water Resources Research, [s.I.], v. 52, n. 6, p.4845-4862, jun. 2016.

GRAFTON, R. Quentin et al. Residential Water Consumption: A Cross Country Analysis. Environmental Economics Research Hub Research Reports, [s.I.], n. 23, p.3-43, 31 ago. 2009.

GIURCO, Damien et al. Developing industrial water reuse synergies in Port Melbourne: cost effectiveness, barriers and opportunities. Journal Of Cleaner Production, [s.I.], v. 19, n. 8, p.867-876, maio 2011.

KANG, Jiyun et al. Sustainable water consumption: The perspective of Hispanic consumers. Journal Of Environmental Psychology, [s.I.], v. 50, p.94-103, jun. 2017.

KATZ, David et al. Evaluating the effectiveness of a water conservation campaign: Combining

experimental and field methods. Journal Of Environmental Management, [s.l.], v. 180, p.335-343, set. 2016.

KOFINAS, Dimitris T.; SPYROPOULOU, Alexandra; LASPIDOU, Chrysi S.. A methodology for synthetic household water consumption data generation. Environmental Modelling \& Software, [s.l.], v. 100, p.48-66, fev. 2018.

KOTLER, P.; ZALTMAN, G.; Social marketing: an approach to planned social change. Journal of Marketing,vol. 35, n³,p.3-12, 1971.

KOTLER, Philip; LEE, Nancy. Social marketing: Changing behaviors for good. Sage, 2016.

KROZER, Yoram et al. Innovations in the water chain - experiences in The Netherlands. Journal Of

Cleaner Production, [s.I.], v. 18, n. 5, p.439-446, mar. 2010. 
LAM, San-pui. Predicting Intentions to Conserve Water From the Theory of Planned Behavior, Perceived Moral Obligation, and Perceived Water Right1. Journal Of Applied Social Psychology, [s.I.], v. 29, n. 5, p.1058-1071, maio 1999.

LAVILLE, Christian; DIONNE, Jean. A construção do saber: manual de metodologia da pesquisa em ciências humanas. Porto Alegre: Artes Médicas Sul; Belo Horizonte: EDUFMG, 1999.

LEE, Nancy; KOTLER, Philip.Social Marketing: Influencing Behaviors for Good. 4 ed. Sage Publications. 2011.

LEVINE, Audrey D.; ASANO, Takashi. Peer Reviewed: Recovering Sustainable Water from Wastewater. Environmental Science \& Technology, [s.I.], v. 38, n. 11, p.201-208, jun. 2004.

LOWE, Ben; LYNCH, David; LOWE, Julian. Reducing household water consumption: a social marketing approach. Journal Of Marketing Management, [s.l.], v. 31, n. 3-4, p. 378-408, 24 out. 2014. MAAS, Alexander et al. Evaluating the effect of conservation motivations on residential water demand. Journal Of Environmental Management, [s.I.], v. 196, p.394-401, jul. 2017.

MARINOSKI, Ana Kelly et al. Usos finais de água em Habitações de Interesse Social no sul do Brasil. Xv Encontro Nacional de Tecnologia do Ambiente Construído, [s.l.], p.0-0, 11 nov. 2014. Marketing Aumentado. http://dx.doi.org/10.17012/entac2014.

MARZANO, Riccardo et al. Determinants of the price response to residential water tariffs: Meta-analysis and beyond. Environmental Modelling \& Software, [s.I.], v. 101, p.236-248, mar. 2018.

MERRIAM, S. B. (2009). Qualitative research: A guide to design and implementation. San Francisco, CA: John Wiley \& Sons.

MOSTAFAVI, Nariman et al. Residential Water Consumption Modeling in the Integrated Urban Metabolism Analysis Tool (IUMAT). Resources, Conservation And Recycling, [s.I.], v. 131, p.64-74, abr. 2018.

NAUGES, Celine; WHITTINGTON, Dale. Evaluating the Performance of Alternative Municipal Water Tariff Designs: Quantifying the Tradeoffs between Equity, Economic Efficiency, and Cost Recovery. World Development, [s.I.], v. 91, p.125-143, mar. 2017.

PHIPPS, Marcus; BRACE-GOVAN, Jan. From Right to Responsibility: Sustainable Change in Water Consumption. Journal Of Public Policy \& Marketing, [s.I.], v. 30, n. 2, p.203-219, nov. 2011. 


\section{Gestãoe \\ Desenvolvimento}

PINGALE, Santosh M.; JAT, Mahesh K.; KHARE, Deepak. Integrated urban water management modelling under climate change scenarios. Resources, Conservation And Recycling, [s.l.], v. 83, p.176-189, fev. 2014.

RANDOLPH, Bill; TROY, Patrick. Attitudes to conservation and water consumption. Environmental Science \& Policy, [s.l.], v. 11, n. 5, p.441-455, ago. 2008.

SHAN, Yixing et al. Household Water Consumption: Insight from a Survey in Greece and Poland. Procedia Engineering, [s.I.], v. 119, p.1409-1418, 2015.

SILVA, Kátia Barbosa da et al. Desperdício de água nas instalações prediais do Campus Universitário da UFCG em Pombal-PB: Medidas para conservação, aproveitamento e reúso. Revista Verde de Agroecologia e Desenvolvimento Sustentável: (Mossoró-RN), Mossoró, v. 8, n. 3, p.221-228, ago. 2013. Trimestral.

VIEIRA, M. M. F. e ZOUAIN, D. M. Pesquisa qualitativa em administração: teoria e prática. Rio de Janeiro: Editora FGV, 2005.

W00D, Matthew. Social Marketing for Social Change. Social Marketing Quarterly, [s.I.], v. 22, n. 2, p.107-118, 17 fev. 2016. 